\title{
El concepto de ironía en la estética de Friedrich Schlegel: contexto y recepción
}

\author{
The concept of irony in the aesthetics of Friedrich Schlegel: \\ context and reception
}

ROSA BENÉITEZ ANDRÉS*

\begin{abstract}
Resumen: La teoría schlegeliana acerca de la ironía continúa siendo un referente indiscutible en los estudios dedicados a este concepto. En el ámbito concreto de la Estética y la Teoría de las artes, la noción de ironía elaborada por F. Schlegel ocupa un puesto privilegiado como herramienta de comprensión y exégesis en los análisis de gran cantidad de prácticas artísticas modernas y contemporáneas. Ante la vigencia de su propuesta, resulta preciso insistir en la particularidad del programa schlegeliano frente a otros usos e interpretaciones del proceder irónico. En tal sentido, este artículo tratará de enfatizar en la especificidad de sus ideas sobre el fenómeno, a través de un recorrido, tanto histórico como teórico, del contexto y recepción de esa ironía romántica planteada por el filósofo, así como por otros autores de la Frühromantik.

Palabras clave: ironía, F. Schlegel, estética romántica, ambigüedad artística y crítica discursiva.
\end{abstract}

\begin{abstract}
The Schlegelian theory of irony remains an unavoidable referent in the studies concerning this concept. In the specific field of Aesthetics and Art Theory, the notion of irony developed by F. Schlegel occupies a privileged position as a tool for both understanding and exegesis within the analysis of a large amount of modern and contemporary art practices. Given the validity of the proposal, it is necessary to insist on the particularity of the Schlegelian program over other uses and interpretations of ironic procedure. Therefore, this paper will attempt to emphasize on the specificity of his ideas about the phenomenon through a historical and theoretical tour around the context and reception of the romantic irony stated by the philosopher, as well as by other authors of the Frühromantik.
\end{abstract}

Keywords: irony, F. Schlegel, romantic aesthetics, artistic ambiguity y discursive critique.

\section{El impulso romántico}

Los albores de la Modernidad no fueron especialmente propicios para el desarrollo de una noción de ironía al menos tan rica como la esbozada por la filosofía y la retórica antigua. Resultó preciso esperar, en este sentido, al impulso que, desde la teoría estética de la Frühromantik y, muy especialmente, gracias a las consideraciones de Friedrich Schlegel, se

Fecha de recepción: 18/05/2014. Fecha de aceptación: 19/06/2014.

* Profesora asociada en la Universidad Complutense de Madrid y la Universidad de Salamanca. Email: beneitezr@usal.es.Principales líneas de investigación: Estética y Teoría de las artes moderna y contemporánea; poesía española contemporánea; vanguardias y neovanguardias y relaciones arte/escritura. 
le confiere a este procedimiento especulativo y discursivo. En efecto, el primer romanticismo alemán encontró en el concepto y la práctica irónica algunas de las respuestas a su interés por fundamentar, en palabras del propio Schlegel, una «poesía trascendental» ${ }^{1}$, esto es, capaz de superar tanto los límites de lo objetivo, como de lo subjetivo. La poesía romántica, en tanto poesía irónica, entrañaba la posibilidad de superar ese antagonismo: recuperar la objetividad perdida, pero sin poner en juego la subjetividad moderna. Ésta debía aunar, por tanto, lo bello con lo interesante en un ideal-realismo o en un realismo-idealista ${ }^{2}$. Sobradamente conocido es ya que en la base de este movimiento filosófico temprano se encuentran tanto el sistema de pensamiento kantiano, como el fichteano. La mayoría de los autores pertenecientes al Círculo de Jena, o muy cercanos a éste, construyeron sus reflexiones a partir de ciertos problemas planteados por Kant - así, Schiller ${ }^{3}$ - o como correlato del tratamiento que Fichte le estaba dando a cuestiones muy similares a las que interesaban a los primeros románticos alemanes, donde se ubicaría, por ejemplo, la propuesta schlegeliana ${ }^{4}$.

Por otra parte, si bien la ironía recobra en este punto de la tradición occidental cierta posición dentro del campo de la filosofía, como ocurría en la Antigüedad clásica, lo cierto es que ahora, además de circunscribirse en el ámbito de la estética, o mejor aún, de la filosofía del arte, y no de la ética, únicamente conservará algunos ecos de la así llamada "ironía socrática" o filosófica. De esta forma, de Sócrates tomarán los románticos la idea de disimulo o fingimiento, es decir, de ficción como modo de cuestionar lo aparente, los juicios ingenuos o la soberbia. Se trata, por tanto, de una metodología que si en Sócrates se encontraba al servicio de una verdad preexistente y, en último término, accesible - buscaba evidenciar el error de aquellas opiniones o juicios aparentemente verdaderos para así lograr acceder a un conocimiento firme sobre lo real-, en el romanticismo adquirirá más bien un carácter dialéctico indefinido y progresivo, casi infinito:

La ironía socrática es el único fingimiento absolutamente involuntario y, sin embargo, absolutamente reflexivo. Tan imposible resulta simularla como revelarla. Para quien carece de ella seguirá siendo un enigma aún después de la más abierta confesión. Su cometido no es engañar a nadie, exceptuando a aquéllos que la consideran un engaño y que, o bien se complacen con la magnífica travesura que consiste en tomar el pelo a todo el mundo, o bien se enojan al sospechar que podría aludirlos. En ella todo debe ser broma y todo debe ser serio, todo debe resultar cándidamente sincero y profundamente simulado a la vez ${ }^{5}$.

1 «Existe una poesía cuyo uno y todo consiste en el vínculo de lo ideal y lo real, y que, por consiguiente, en analogía con la jerga filosófica, tendría que llamarse poesía trascendental», Schlegel, F., «Fragmentos del Athenaeum, 1798» (238), en: Fragmentos, seguido de Sobre la incomprensibilidad, Barcelona, Marbot, 2009, p. 114 (de ahora en adelante, el número de fragmento será citado entre paréntesis al comienzo de la referencia bibliográfica).

2 Cf. Szondi, P., Poética y filosofía de la historia I, Madrid, Visor, 1992, pp. 73-75.

3 Véase al respecto el excelente análisis que José Manuel Cuesta Abad dedica a la asimilación de la filosofía kantiana en el pensamiento schilleriano: Cuesta Abad, J. M., «Dialéctica sentimental. Schiller agonista», en: La transparencia informe. Filosofía y literatura de Schiller a Nietzsche, Madrid, Abada, 2010, pp. 13-77, en especial, pp. 29-44.

4 Cf. D’Angelo, P., La estética del romanticismo, Madrid, Visor, 1999.

5 Schlegel, F., «Fragmentos críticos, 1797» (108), en: Fragmentos, ed. cit., pp. 48-49. 
Sin embargo, la idea y función de la ironía propuestas por Friedrich Schlegel, a quien pertenecen las palabras aquí recogidas, irán mucho más allá del planteamiento epistemológico socrático. La ironía va a ser para éste una estrategia discursiva y de pensamiento con la que poner en cuestión los vínculos entre lo objetivo y lo subjetivo, lo finito y lo infinito, lo real y lo ideal. Este enfoque será en buena medida compartido, aunque con algunas diferencias, por otros de los autores pertenecientes a la Frühromantik que, en sintonía con Schlegel, dieron un tratamiento especial a la ironía en sus escritos. Conviene, por tanto, detenerse en ellos para comprender de un modo más preciso el origen y alcance de la teoría schlegeliana sobre la ironía.

August Wilhelm Schlegel, a diferencia de Friedrich, entenderá la ironía más como una técnica artística que como una actitud cognitiva. En sus Lecciones de literatura y arte dramático de 1808 y 1809, el mayor de los Schlegel ve en la ironía un elemento privilegiado del género cómico y excluido del trágico. Mantiene, eso sí, al igual que harán Schelling o Novalis, la idea de que aquélla es una forma de autoconciencia artística:

Consiste la ironía en «comprender, de forma más o menos clara, que la representación es parcial y exagerada y que en ella hay una gran parte de sentimiento y fantasía». Con la ironía demuestra el artista su superioridad sobre los materiales de que se sirve, «y que, si así lo deseara, podría aniquilar sin piedad esa hermosa ilusión, de tan irresistible atractivo, que él mismo hizo nacer con sus conjuros» ${ }^{6}$.

También para Tieck y Jean Paul la ironía constituye una ruptura de la ilusión y, por tanto, hace referencia a la capacidad del sujeto (tanto del creador como del público) para sobreponerse y mantener una postura distanciada ante la representación. Ambos la circunscriben al género o la actitud cómica, desde donde le otorgan un papel eminentemente crítico. En el caso del primero, y dada su condición de escritor, se hace especialmente evidente el uso de lo irónico en tanto que mecanismo de interrupción. Algunas de sus obras de teatro, como El gato con botas o El mundo al revés, constituyen una verdadera puesta en práctica y tematización de las teorías románticas:

-Rey: Me encanta extender la vista libremente a través de la hermosa naturaleza.

-Princesa: ¿Y llega muy lejos la vista?

- Rey: ¡Oh, sí! Y si no fuera por todas esas fatídicas montañas, se vería aún más lejos. ¡Ay que dolor, el árbol está lleno de orugas!

-Princesa: Es que se trata de una naturaleza todavía sin idealizar; primero ha de ennoblecerla la fantasía.

- Rey: Ahora desearía que tú, con tu fantasía, me pudieras librar de las orugas ${ }^{7}$

6 Wellek, R., Historia de la crítica moderna (1750-1950). Tomo II. El Romanticismo, Madrid, Gredos, 1962, p. 66 (las palabras entrecomilladas pertenecen a August Wilhelm Schlegel, las cuales reproducimos aquí a partir de Wellek a falta de una traducción al castellano).

7 Tieck, L., El gato con botas, Madrid, Abada Editores, 2003, p. 104. 
Por su parte, Jean Paul insistirá nuevamente en el carácter humorístico de la ironía, puesto que, más allá de sus escritos literarios, es éste el tema que ocupa su reflexión estética, es decir, las particularidades de lo cómico romántico y lo humorístico. Para Jean Paul, el humor constituye una suerte de «sublime invertido», un encuentro entre lo romántico (infinitud del sujeto) y lo cómico (lo finito del mundo material) donde se objetiva la distancia entre lo necesario y lo contingente ${ }^{8}$. Tal perspectiva sobre lo humorístico, que parecería discurrir en paralelo a las ideas expuestas por Schlegel acerca de la ironía, rechaza sin embargo el valor de cualquier actividad caracterizada como irónica. Así, la ironía no recibe aquí un tratamiento positivo, y es valorada, por el contrario, en tanto que apariencia de seriedad y fenómeno estrictamente retórico-lingüístico. Se trata pues de un mecanismo que, para Jean Paul, a pesar de tener cierta relación con lo que él mismo entiende por humor, no alcanza las cotas de universalidad logradas por éste ${ }^{9}$. En este sentido, no fue Jean Paul el único autor de la época en menospreciar la centralidad que algunos de sus coetáneos le habían otorgado a la ironía. Quizá, el caso más conocido y exagerado de rechazo absoluto respecto a los planteamientos schlegelianos, y de otros románticos, fuera el de Hegel. Según este filósofo, la disolución artística propia a la forma romántica, celebrada por estos autores, implica a su vez una desustancialización consciente y voluntaria de todo lo que debería ser esencial en la obra de arte. Entiende, por ello, que el ejercicio de la ironía no es más que otra de las fórmulas con las que propagar la inadecuación entre «figura» e «idea», presente en las artes de su tiempo, es decir, la pérdida del ideal:

Contra la exigencia de colocar en lo más alto algo substancial, ético, verdadero en y para sí, en segundo lugar se dirige ante todo la consideración formal, cuya alma es la ironía. Lo substancial no se convierte en lo principal, sino que otros puntos de vista son antepuestos con agudeza e ingenio ingeniosamente - algo incorrecto, aunque haya que prestarles atención. [...] La ironía trae consigo que nada pueda tomarse en serio, y cuando comienza lo serio nada resulta; los bribones se convierten en gente excelente, y los honestos en bribones ${ }^{10}$.

Obviamente, aquello que más molesta a Hegel de la ironía romántica es su gusto por la ambigüedad, que nada sea lo que parece y que la indefinición reine en toda propuesta formal y temática. La estética hegeliana se fundamenta en la unión entre realidad y concepto, esto es, la idea, y la apariencia de lo sensible que hay en ella. Por tanto, el hecho de que se "juegue" con todo tipo de ilusiones y disimulos es considerado por el filósofo como una muestra de imperfección. Asimismo, si se tratara de situar todo este entramado de desequilibrios en relación al conjunto del pensamiento hegeliano, la ironía no saldría mucho mejor parada, ya que la defensa de la paradoja, el caos o la parábasis realizada

8 «Consistiendo lo cómico en la destrucción del contraste que existe entre los dos principios, el subjetivo y el objetivo, y según hemos dicho, debiendo ser el principio objetivo un infinito del que deseamos apoderarnos, no puedo imaginar ni poner este principio fuera de mí, sino que lo coloco en mí mismo, donde lo sustituyo con el principio subjetivo. [...] divido mi yo en dos factores, el finito y el infinito, y hago emanar éste del primero», Richter, J. P., Introducción a la estética, Madrid, Verbum, 1991, p. 101.

9 Cf. Ibíd., p. 94.

10 Hegel, G. W. F., Filosofía del arte o Estética. Verano de 1826, Madrid, Abada Editores / UAM Ediciones, 2006 , p. 531 . 
por Schlegel no sólo irritaría a Hegel por ser una amenaza contra su sistema, sino por ser una amenaza contra cualquier sistema ${ }^{11}$.

A pesar de todo ello, sí existe una ironía con la que Hegel logra ponerse de acuerdo. Se trata, en concreto, de la concepción mantenida por otro romántico: Karl Wilhelm Ferdinand Solger ${ }^{12}$. Para este autor lo ideal en la obra de arte no sería un producto del artista, sino «la revelación sensible de algo divino» ${ }^{13}$; postura con la que evita cualquier acusación de subjetivismo relativista, tal y como Hegel hacía con Schlegel. En su Erwin. Cuatro diálogos sobre lo bello y el arte, Solger describe la ironía como una suerte de transitoriedad artística - «nadería» - donde, gracias al carácter simbólico del arte, lo universal y lo singular, lo esencial y lo real, quedan unidos en la ilusión estética. El artista, consciente de las fuertes contradicciones de su mundo, trata de que éstas queden superadas mediante el uso de la ironía. Por tanto, esta última debería ser, desde la perspectiva de Solger, la aspiración y principio rector de todo arte, pues sólo mediante el empleo de tal disposición resultaría posible lograr una adecuada armonización de contrarios y, de este modo, la superación de las limitaciones propias a la existencia humana en contraposición a la divina ${ }^{14}$. Así, la ironía, que en este escrito queda vinculada a una de las formas con las que el hombre se relaciona con el mundo, a saber, el arte - a la que habría que añadir, según Solger, la religión, la moral y la filosofía - se postula como un modo de conocimiento: «el temple de ánimo que ilumina esa presencia inmediata de lo divino en las cosas humanas» ${ }^{15}$. No obstante, si bien en Solger la ironía se hace con un papel protagonista dentro de su teoría, tal significación no llevará de ningún modo a que ésta termine por emparentarse con la ironía schlegeliana, la cual también constituía el centro de las reflexiones del joven Schlegel. Nada tendrían que ver, en este sentido, la propuesta de Solger, quien defiende la conciliación de contrarios, con la infinita suspensión dialéctica a la que aspiraba Schlegel. De ahí que, por otra parte, al igual que hiciera Hegel, Solger ataque la ironía de F. Schlegel por considerarla «bufonesca, subjetivista, cínica e irresponsable» ${ }^{16}$, ignorando con ello su parte objetiva y, por tanto, el movimiento de superación del individualismo. Unas críticas al concepto desarrollado por Schlegel que parecen extenderse más allá de su contexto más inmediato y que han determinado tanto la lectura que muchos otros autores han realizado del filósofo alemán, como el alcance de la propia noción de ironía en nuestra tradición.

11 Véase: Hernández Sánchez, D., La ironía estética. Estética romántica y arte moderno, Salamanca, Ediciones Universidad de Salamanca, 2002, p. 66.

12 «mi difunto colega Solger presenta en su Erwin a la ironía como la suprema determinación del arte. Con respecto a lo en él peculiar, a sus escritos póstumos, quiero insistir en que él partió de la necesidad especulativa, y que desde la filosofía auténtica alcanzó el punto que yo llamo infinita, absoluta negatividad. Ese punto cuenta, sin duda, como momento absoluto en la idea misma; el punto al que llegó es, por tanto, un verdadero momento en la idea, pero una cosa es [ser] momento de la idea y otra que exprese la determinidad de toda la idea. Hay que señalar, además, que la vida de Solger se ha quebrado demasiado pronto como para que pudiera llegar a una formación concreta; alcanzó únicamente el punto abstracto de la negatividad, sin poder desarrollarla», Hegel, G. W. F., Filosofía del arte o Estética. Verano de 1826, ed. cit., p. 95.

13 Sánchez Meca, D., «Friedrich Schlegel y la ironía romántica», Er. Revista de Filosofía (Barcelona), n 26, 1999, p. 110.

14 Cf. Wellek, R., Historia de la crítica moderna (1750-1950). Tomo II. El Romanticismo, ed. cit., pp. 334-340.

15 Solger, K. W. F., Erwin. Vier Gespräche über das Schöne und die Kunst, traducción citada en Henckmann, W., «El concepto de ironía en K. W. F. Solger», Enrahonar (Barcelona), n 14, 1988, p. 22.

16 Wellek, Rene, Historia de la crítica moderna (1750-1950), ed. cit., p. 337. 


\section{Los (des)acuerdos}

Dejando para más adelante las especificidades de la ironía del primer Schlegel, quien en un segundo momento de su carrera abandonará la mayor parte de los presupuestos adoptados en sus investigaciones iniciales, para consagrar su estudio al mundo oriental y, después, al cristianismo, se hace preciso ahora constatar que la mayoría de tratamientos sobre la ironía posteriores a él basarán su reflexión en el rechazo de aquélla, como ya hicieran algunos de sus coetáneos. Así, por ejemplo, Kierkegaard criticará la ironía de Schlegel y Tieck por su frivolidad y arbitrariedad ${ }^{17}$. Siguiendo en este punto los reproches de Hegel a la ironía romántica, el filósofo danés afirma que:

Con Fichte, la subjetividad había llegado a ser libre, infinita, negativa. Sin embargo, para salir de ese movimiento inconsciente en el que se agitaba en infinita abstracción, debía ser negada; para hacerse real, el pensamiento debía hacerse concreto. Con esto surge la pregunta concerniente a la realidad metafísica. Schlegel y Tieck tomaron el principio fichteano según el cual la subjetividad o el Yo posee valor constitutivo y es el único omnipotente, y a partir de allí operaron en el mundo ${ }^{18}$.

Y así, continúa Kierkegaard, estos autores confundieron el yo empírico con el eterno o ideal y la realidad metafísica con la histórica, dando como resultado una realidad «autoengendrada» que, a pesar de haber surgido como resultado de la crítica - de la negación irónica - , reduce todo lo existente a la pura nada y se convierte en una ficción (ámbito en el que, como se verá, cifra Schlegel el poder de la ironía), que deja sin resolver el conflicto entre lo real y lo ideal; lugar de donde precisamente surge el impulso irónico. Frente a esta ironía «abstracta, metafísica y estética» ${ }^{19}$, Kierkegaard trata de recuperar, al igual que hiciera Hegel, las virtudes de la ironía socrática y, en particular, su apuesta por la negatividad como modo concreto y efectivo de modificación de la realidad. Para ello, se refiere a un tipo de «dialéctica negativa ${ }^{20}$ que mantiene en suspenso el conflicto real-ideal y que, gracias a esta no resolución, logra una aproximación más consecuente entre ambos polos que la aportada por la superación del momento negativo. Sin embargo, a pesar de esta revalorización de la ironía socrática, Kierkegaard propone ir más allá de la negatividad y subjetividad propias a esta última mediante la práctica de cierta «simpatía» ${ }^{21}$. De este modo, terminará por oponer a la ironía el humor cristiano y un tipo de «dialéctica cualitativa» basada en la afirmación y multiplicación de respuestas positivas posibles, en relación a la existencia ${ }^{22}$. Por tanto, ante la imposibilidad de una puesta en práctica constante de la ironía, el filósofo danés optará por que el humor haga patente la ironía de la realidad, es decir, el hecho de que ésta no coincida

17 Kierkegaard, S., «Sobre el concepto de ironía», en: Escritos, vol. 1, Madrid, Trotta, 2000, pp. 307-324.

18 Ibíd., p. 298.

19 Ibíd., p. 305.

20 Ibíd., p. 196.

21 Ibíd., p. 235.

22 Para un tratamiento concreto de estas cuestiones, véase: Llevadot, L., «Negatividad: La figura de Sócrates en la obra de Kierkegaard», Contrastes. Revista Internacional de Filosofía (Málaga), nº 14, 2009, pp. 269280 . 
nunca con la idea. A su vez, Kierkegaard insiste en proponer una cantidad ilimitada de afirmaciones, por muy contradictorias que sean, con las que no sucumbir ante la «negatividad infinita y absoluta» ${ }^{23}$, esto es, la nada.

Se ha apuntado aquí una línea que comienza en la Antigüedad clásica, y que permanece casi intacta a lo largo de la Modernidad, donde muchas de la aproximaciones a la noción de ironía resaltan su parentesco con lo cómico o humorístico. Si al continuar con el desarrollo filosófico de este concepto se llegaba a la figura de Kierkegaard y sus matizaciones al planteamiento socrático, de Schlegel o Hegel, resulta igualmente necesario referirse ahora a otro detractor del hegelianismo, aunque anterior al danés, y defensor del carácter cómico de la ironía: Arthur Schopenhauer. En su «Sobre la teoría de la risa», este autor destaca la función perturbadora de aquélla, relacionándola, de este modo, con el ya mencionado conflicto entre idea y realidad, subjetividad y objetividad o, como dice el propio Schopenhauer, «lo pensado y lo intuido» ${ }^{24}$. El objetivo de este filósofo no es otro que el de localizar el origen de la risa que, según su interpretación (de raíz kantiana), reside en «la paradójica y, por tanto, inesperada subsunción de un objeto bajo un concepto por lo demás heterogéneo a él [...] la repentina percepción de una incongruencia entre tal concepto y el objeto real pensado con él, es decir, entre lo abstracto y lo intuitivo» ${ }^{25}$.

Enmarcada en su teoría del conocimiento, Schopenhauer entiende la risa como un indicador más de las diferencias entre representaciones intuitivas y abstractas. Por ello, el filósofo establece dos direcciones en lo risible, en función de si la representación va del objeto al concepto o del concepto a lo real. Dentro de esta sistematización, la ironía no es más que otra de las fórmulas con las que incitar a la risa, como ocurre con la paradoja, el chiste, etc. Ahora bien, existen dos rasgos destacables en la caracterización que Schopenhauer hace de la ironía. Por un lado, y como especie de lo risible que se produce cuando la representación se establece de lo intuido a lo pensado, el autor habla de un tipo de conceptualización intencionada en la que el sujeto coloca «una cosa real e intuitiva directamente bajo el concepto de su contrario», destacando que con ello «surge entonces la trivial y vulgar ironía» ${ }^{26}$. Es decir, Schopenhauer establece aquí un juicio de valor negativo sobre la ironía; en concreto, sobre la ironía que se limita a establecer una relación de contrarios entre lo percibido y lo conceptualizado. Aunque, por otra parte, y ahora ya bajo la forma opuesta de representación - la que va del concepto a la cosa-, el filósofo se refiere a otra ironía sin duda más compleja que la anterior, y más cercana al concepto de Schlegel, que descansa en una alteración o desequilibrio mayor. Así, en su comparación con lo humorístico, Schopenhauer destaca la seriedad fingida propia a la ironía, en detrimento de la alegría con la que se asocia el humor, pero precisamente para hacer constar que al igual que la seriedad de la ironía es sólo aparente, también la risa conduce en última instancia a un estado de ánimo mucho más grave o pesaroso que el de despreocupación inicial ${ }^{27}$.

23 Kierkegaard, S., «Sobre el concepto de ironía», en: Escritos, vol. 1, ed. cit., p. 287.

24 Schopenhauer, A., El mundo como voluntad y representación, vol. 2, Madrid, Trotta, 2000, p. 123.

25 Ibíd., pp. 122-123.

26 Ibíd., p. 126.

27 «Lo intencionadamente irrisorio es la broma: es el empeño por abrir camino a una discrepancia entre los conceptos de otro y la realidad, dislocando una de las dos cosas; mientras que su opuesto, la seriedad, consiste en una exacta concordancia entre ambos, al menos pretendida. Mas cuando la broma se esconde tras la seriedad, 
Por tanto, nos encontramos de nuevo con que el humor se impone a la ironía - como ocurría, por ejemplo, en Jean Paul o Kierkegaard-, pues a pesar de ser entendido aquí como un procedimiento mucho más subjetivo que la ironía (se vuelve contra el sujeto que lo practica, no como la ironía que, para el filósofo, se dirige siempre hacia los demás), aparece definido como «el doble contrapunto de la ironía». En todo caso, sobresale esa positiva consideración de la práctica irónica, al entender que todos estos procedimientos cómicos (Schopenhauer aboga por la identidad entre lo cómico y lo humorístico ${ }^{28}$ ) contribuyen a poner límites a una razón extremadamente especulativa: «ver por una vez a la razón, esa mentora estricta, infatigable y cargante, ser declarada culpable de insuficiencia» ${ }^{29}$. Sin duda, esta caracterización de la ironía como incongruencia risible, ya presente en Aristóteles, experimentará una gran aceptación en buena parte de las posteriores consideraciones sobre el fenómeno, influyendo en otros autores como Baudelaire o Bergson, los cuales centraron su reflexión en torno a lo cómico y la risa ${ }^{30}$.

Finalmente, uno de los últimos acercamientos filosóficos a la ironía, emparentado con las teorías románticas ${ }^{31}$, y casi contemporáneo a los nuevos enfoques gestados en la Lingüística y la Teoría de la literatura, es el encarnado precisamente por un discípulo de Henri Bergson: Vladimir Jankélévitch. Como buen conocedor de la filosofía romántica (en especial de Schelling), este autor rescató algunas de las acepciones que aquéllos habían dado a la ironía (ambigüedad expresiva, fragmentariedad, contención, etc.), si bien no dudó en criticar muchas de sus posturas. Así, siguiendo la línea interpretativa que se abría en función del rechazo a la teoría schlegeliana - la cual aparecía como una constante en los acercamientos anteriores - Jankèlevitch tampoco renunciará a cuestionar los excesos del joven alemán, por mucho que sus consideraciones estén en deuda con él. Por otra parte, vuelve a surgir aquí la dialéctica o conflicto entre el ser y el parecer donde opera la ironía, que ahora además se extiende hasta otros binomios:

la ambigüedad de la Apariencia, siempre a mitad de camino entre el Ser y el No Ser, nos inspira una saludable desconfianza que, como veremos, es el ABC de la ironía. [...] por supuesto, la apariencia no es la realidad, y sin embargo contiene algo que es relativamente verdadero; participa de lo real; más exactamente: es algo distinto de lo que anuncia; pero... algo distinto sigue siendo algo. [...] Este equívoco del Parecer

entonces nace la ironía [...] Lo inverso de la ironía sería entonces la seriedad oculta tras la broma, y eso es el humor. Se lo podría designar como el doble contrapunto de la ironía. [...] Si la ironía comienza con un gesto serio y acaba riendo, en el humor ocurre lo contrario», Ibíd., p. 131.

28 Para un análisis de las relaciones entre los conceptos de comicidad y humor, véase: Critchley, S., Sobre el Humor, Torrelavega, Quálea, 2010, pp. 96-99.

29 Schopenhauer, A., El mundo como voluntad y representación, ed. cit., p. 130.

30 En relación al papel de la ironía en estos autores, véase: Ballart, P., Eironeia. La figuración irónica en el discurso literario moderno, Barcelona, Quaderns Crema, 1994, pp. 119-136.

31 Obviamente, no será el único pero sí quizá uno de los que haga de ella la piedra angular de su propuesta moral. Otros tratamientos importantes en el siglo XX, aunque desde muy diversas perspectivas y que, en algunos casos, serán tratados con posterioridad, serían los de Lukács, G., Teoría de la novela, Barcelona, Edhasa, 1971; Benjamin, W., El concepto de crítica de arte en el Romanticismo alemán, en: Obras, libro I/vol. 1, Madrid, Abada, 2007; Rorty, R., Contingencia, ironía y solidaridad, Barcelona, Paidós, 1991; Barthes, R., Crítica y verdad, Madrid, Siglo XXI, 2005 o Man, P. de, La ideología estética, Madrid, Cátedra, 1998 y Visión y ceguera. Ensayos sobre la retórica de la crítica contemporánea, Río Piedras, Universidad de Puerto Rico, 1991. 
y el Aparecer posibilita los escamoteos de la conciencia. La conciencia explota con virtuosismo la disociación de la apariencia y el ser: así como las cualidades percibidas no se parecen a la esencia noética, tampoco las ideas se parecen a las palabras, o el dicho al hecho. ¡Desacuerdo del pensamiento con el lenguaje, desacuerdo del pensamiento con la acción, y, por último, desacuerdo del pensamiento consigo mismo! ${ }^{32}$.

La ironía constituye para Jankélévitch una forma de conciencia superior, a la que califica de «buena» por poseer un marcado carácter moral ${ }^{33}$, y que viene determinada por su condición desinteresada y distanciada. Al sustraerse a la urgencia o necesidad de alcanzar un fin, establecer fronteras o abarcarlo todo, logra superar algunas de las limitaciones propias al modo en que el hombre conoce su realidad; le permite tomar distancia de los objetos pero también de su propia mente, en un proceso en el que la conciencia se contempla a sí misma. A pesar de las similitudes que esta descripción parecería guardar con ciertos planteamientos románticos, Jankélévitch rechaza rotundamente el subjetivismo achacado a aquéllos. Asimismo, y a diferencia del resto de interpretaciones expuestas hasta aquí, este autor establece una radical separación entre arte e ironía y afirma que al primero le faltaría el momento crítico, aquel movimiento que vuelve sobre sus propios pasos para deshacer parte de lo alcanzado. El arte es, para Jankélévitch, una conciencia extremadamente tranquila que no consigue revocar o destruir lo aparente como sí haría la ironía ${ }^{34}$. Por último, y en sintonía con otros autores como Jean Paul, Schopenhauer o Kierkegaard, también Jankélévitch hará hincapié en la superioridad del humor frente a la ironía, o al menos de una «ironía humorística» en detrimento de la simplemente $\operatorname{mordaz}^{35}$.

De este modo, la ironía no será para este autor ni trágica, ni cómica, sino más bien tragicómica y, por tanto, «lo-uno-y-lo-otro más que ni-lo-uno-ni-lo-otro» ${ }^{36}$. Además, como en las antiguas retóricas, vuelve a relacionar ironía y alegoría al rechazar una teoría realista de la expresión y subrayar la distancia que media entre pensamiento y lenguaje ${ }^{37}$. También defiende una concepción antifrástica ${ }^{38}$ de la ironía mucho más radical que la promulgada por las teorías clásicas y que, sin duda, entra en conflicto con la versatilidad de cierta ironía romántica.

32 Jankélévitch, V., La ironía, Madrid, Taurus, 1986, p. 49.

33 Para este autor conocer lo verdadero y conocer lo bueno representaría un mismo movimiento de la conciencia. Así lo ha apuntado, por otra parte, Pierre Schoentjes: «Jankélévitch, que intenta hacer coincidir la conciencia intelectual y la conciencia moral, no dejará de explotar esta ambigüedad», Schoentjes, P., La poética de la ironía, ed. cit., p. 40.

34 Jankélévitch, V., La ironía, ed. cit., pp. 50-51.

35 «Es una ironía a la segunda potencia y que en ella la relación "alegórica" se muestra doblemente indirecta; es una suprema reflexión de la conciencia. Si la ironía simple oculta una verdad simple tras la apariencia transparente de la seriedad, la ironía humorística, en cambio, alude a la impalpable seriedad de la apariencia [...] El ironista sin humor empieza gravemente, después se echa a reír y deshace todo lo que ha hecho: o sea, que basta una lectura directa para descifrar, a contrario, su verdad; el ironista humorizante, en cambio, se hace el que nos engaña, porque simula la simulación e ironiza sobre la ironía», Ibíd., p. 151.

36 Ibíd., p. 116.

37 Ibíd., p. 40.

38 Jankélévitch lo denomina antegoría: «Entre las diversas posibilidades que le presenta la inteligencia, la ironía elige la alteridad más extrema: no expresa, como cualquier alegoría, algo distinto de lo que piensa, sino lo contrario de lo que piensa, o sea, lo distinto, lo distinto por excelencia. En eso es antegoría», Ibíd., p. 65. 
Ahora bien, a pesar de esta cuasi-constante oposición a las teorías de los integrantes de la Frühromantik, en especial a las de F. Schlegel, lo cierto es que la mayoría de los enfoques desarrollados tras estos pensadores mantienen una deuda tal con aquellos planteamientos que obliga a continuar entendiéndolos como elementos definitorios, incluso, en la comprensión actual de la ironía. No en vano, fue la recuperación obrada por los románticos la que permitió comenzar a hablar, de un modo más preciso, del carácter literario o artístico de la ironía; de su vínculo con lo trágico o lo cómico; de la capacidad para estructurar nuevas vías cognoscitivas en las que se fundamenta o de su carácter ambivalente. Por tanto, si efectivamente las perspectivas generadas desde ese ámbito de reflexión filosófica ayudaron a interpretar determinadas estrategias irónicas que escapaban o iban más allá de la simple inversión de contrarios o el disimulo (interpretaciones más habituales desde los inicios de la reflexión sobre el concepto), y se situaron, además, en un plano de análisis completamente dependiente del hecho artístico, necesariamente habrán de servir como base para comprender ese campo de complejas tensiones que ciertos usos de la ironía continúan manteniendo en la actualidad.

\section{La ironía schlegeliana}

Como se apuntaba, las estéticas de Novalis, Schelling o F. Schlegel basan buena parte de sus principios en la concepción fichteana del «saber absoluto» como reflexión, la cual entiende esa autoconciencia del sujeto en tanto que forma primordial, inmediata y cierta del pensamiento: «referida al sujeto, la reflexión expresa, por un lado, su aislamiento, al hacer a este sujeto objeto para sí mismo ahondando en su separación. Pero, por otro lado, el sujeto se contempla a la vez que contempla el mundo, superando así, en esta contemplación, la escisión que la reflexión misma introduce» ${ }^{39}$. No obstante, y siguiendo aquí la interpretación de Walter Benjamin sobre sus planteamientos - que, en cierto modo, desacredita los reproches de Kierkegaard, recientemente reseñados - , resulta preciso hacer notar que los integrantes del Círculo de Jena sustituyeron el «yo» de Fichte, como centro de la reflexión (o pensamiento del pensamiento), por el arte: «La intuición romántica del arte estriba en el hecho de que por pensar del pensar no se entiende ninguna conciencia del yo. La reflexión libre del yo es una reflexión en el absoluto del arte $»^{40}$. De este modo, para los mencionados autores, tal ejercicio de reflexión, en el que el sujeto logra liberarse (aunque sea momentáneamente) de toda determinación, ha de entenderse dentro de un ámbito estrictamente creativo. Así, en Schlegel, la forma en la que el yo accede al conocimiento absoluto debe circunscribirse dentro del medio artístico y no puramente intelectual o de la lógica, como en Fichte. Anota, así, en el Diálogo sobre la poesía de 1800:

LUDOVICO. La representación (Vorstellung) interior sólo por la representación (Darstellung) exterior puede hacerse más clara a sí misma y enteramente viviente.

39 Sánchez Meca, D., «Friedrich Schlegel y la ironía romántica», art. cit., p. 90.

40 Benjamin, W., El concepto de crítica de arte en el Romanticismo alemán, en: Obras, libro I/vol. 1, ed. cit., p. 41 . 
MARCOS. Y la representación (Darstellung) es cosa del arte, si se quiere como si no se quiere ${ }^{41}$.

Para aquél, entonces, es el arte el que permite al espíritu desarrollarse libremente gracias a un proceso de creación y autodestrucción constante ${ }^{42}$. En palabras de Diego Sánchez Meca: «Si para Fichte, la mediación entre el yo y el mundo es la conciencia, para Schlegel es el arte, con lo que el yo, en vez de ponerse como conciencia absoluta, como absoluta subjetividad, se exterioriza, sale de sí mediante la comunicación y la creatividad, cuyo médium es el lenguaje como arte, es decir, la poesía» ${ }^{43}$. Es importante tener en cuenta que, por un lado, el lenguaje está siendo entendido aquí no como simple vehículo que trasmite una realidad dada, sino como agente productor de sentido. Pero, por otro lado, resulta igualmente necesario resaltar que ese medio lingüístico es, asimismo, el que procura al sujeto la posibilidad de mantener una posición dialéctica con respecto a lo real, en la que se aúnan el momento subjetivo de la expresión, con el objetivo de la reflexión sobre él mismo (el espíritu es a la vez productor y producto). Es éste el sentido de la conocida sentencia de Schlegel según la cual «La poesía romántica es una poesía universal progresiva», fragmento donde unas líneas más adelante se especifica que ésta

puede flotar, con las alas de la reflexión poética entre lo representado y lo representante, quedándose suspendida entre ambos, libre de todo interés real o ideal, y elevar a la potencia una y otra vez esa reflexión, multiplicándola como una serie infinita de espejos. Al organizar todo aquello que en sus productos debe constituir un todo, es capaz de la forma más elevada y universal (y no sólo de dentro hacia fuera, sino también de fuera hacia adentro), por lo que abre la perspectiva de un arte clásico capaz de crecer sin límites. [...] se encuentra todavía en devenir; y precisamente en esto consiste su verdadera esencia: en que sólo puede devenir eternamente, nunca puede consumarse ${ }^{44}$.

Con tales planteamientos de fondo, se evidencia que, para Schlegel, la poesía - y poesía ha de entenderse aquí en un sentido similar al que actualmente le damos a la literatura y no únicamente como género lírico - representa el vínculo más genuino del hombre con la realidad, puesto que en ella el sujeto cumple con la exigencia de ser, al tiempo, quien determina y el determinado. Pero, también, se comprende que para que la balanza no se incline del lado subjetivo, ni del objetivo, la creación poética ha de estar en continuo devenir, en un proceso de afirmación y negación constante. Siguiendo la propuesta schlegeliana, sólo este devenir reflexivo entre lo condicionado y lo incondicionado permite al yo eludir los peligros de caer bien en un subjetivismo relativista, o bien en un informe heterónomo no menos limitado que

41 Schlegel, F., Poesía y filosofía, Madrid, Alianza, 1994, p. 115.

42 Así lo resumía Schleiermacher en uno de los fragmentos del Athenäum no atribuidos a Schlegel: «Sólo quien se pone a sí mismo puede poner a otros. Del mismo modo, sólo quien se aniquila a sí mismo tiene derecho a aniquilar a cualquier otro», Schleiermacher, F., «Fragmentos del Athenaeum, 1798» (328), en: Schlegel, F., Fragmentos, ed. cit., p. 114.

43 Sánchez Meca, D., «Estudio preliminar», en: Schlegel, F., Poesía y filosofía, ed. cit., p. 15.

44 Schlegel, F., «Fragmentos del Athenaeum, 1798» (108), en: Fragmentos, ed. cit., pp. 81-82. 
el anterior. La corrección de ambos excesos - el de la biografía y el de la crónica, dentro del ámbito literario, por ejemplo - esta encarnada, aquí, por la autolimitación:

Para poder escribir bien sobre un asunto es necesario que ya no tenga ningún interés para nosotros; aquel pensamiento que debemos expresar reflexivamente ha de ser agua pasada y no debe seguir ocupándonos. Mientras inventa y está inspirado el artista se encuentra con respecto a la comunicación en un estado, cuando menos, iliberal. Entonces lo querrá decir todo (lo cual constituye una tendencia equivocada propia de genios jóvenes, cuando no un justo prejuicio de viejos ineptos), y no apreciará el valor y la dignidad de la autolimitación, que para el artista, igual que para el ser humano en general, constituye lo primero y lo último, lo más necesario y lo más elevado. Lo más necesario, pues cuando no nos ponemos límites a nosotros mismos, es el mundo el que nos limita y acabamos, así, convertidos en esclavos. Y lo más elevado, porque sólo podemos limitarnos en aquellos puntos y en aquellas facetas en los que poseemos un fuerza infinita, la facultad de autocreación y autoaniquilación. [...] Sólo hay tres peligros de los que tenemos que guardarnos. Primer peligro: lo que parece y debe parecer arbitrariedad incondicionada y, por ende, irracionalidad o ultrarracionalidad, debe ser, no obstante y en el fondo, absolutamente necesario y racional; de lo contrario, el estado de ánimo degenera en capricho, surge la iliberalidad y la autolimitación acaba convertida en autodestrucción. Segundo: debemos procurar no apresurarnos demasiado con la autolimitación y dejar primero espacio a la autocreación, esto es, a la invención y el entusiasmo, hasta que haya concluido. Tercero: no debemos excedernos en la autolimitación ${ }^{45}$.

Se alude aquí a uno de los puntos cardinales de la estética de la Frühromantik, además de su gran desconocido o, al menos, de su componente peor interpretado. En efecto, el romanticismo ha pasado a la Historia de la cultura como un movimiento artístico entregado a la expresión de una subjetividad genial, que pretendía asumir el papel de guía sentimental para la sociedad ${ }^{46}$. Y, aunque en buena medida, tal caracterización podría aplicarse a ciertas actitudes estéticas de determinadas corrientes románticas, lo cierto es que el primer romanticismo alemán aspiraba a mantener un complejo equilibrio entre entusiasmo y contención o, en palabras del propio Schlegel, a que lo ingenuo - recurriendo aquí a la conocida distinción propuesta por Schiller ${ }^{47}$ - fuera «al mismo tiempo instinto e intención» ${ }^{48}$. Tal como se vio,

45 Schlegel, F., «Fragmentos críticos, 1797» (37), en: Fragmentos, ed. cit., pp. 32-33.

46 Contra esta concepción ya se manifestaba Schlegel en su «Diálogo sobre la poesía» del año 1800: «según mi parecer y mi terminología, romántico es lo que nos representa una materia sentimental en una forma fantástica. Olvida por un instante el usual y peyorativo significado de sentimental, en el que, bajo esta denominación, se entiende todo lo que es vulgarmente conmovedor y lacrimógeno, impregnado de aquellos sentimientos familiares, en la conciencia de los cuales, hombres sin carácter se sienten tan indeciblemente dichosos y grandes», Schlegel, F., Poesía y filosofía, ed. cit., p. 133.

47 Schiller, F., Sobre poesía ingenua y poesía sentimental, Madrid, Verbum, 1995. Para un análisis de la asimilación de estos términos en la teoría de Schlegel, véase: Szondi, P., Poética y filosofía de la historia I, ed. cit., pp. 70-71.

48 «Si se trata de mero instinto, entonces es pueril, infantil o bobo; en cambio, si se trata de pura intención lo que surge entonces es la afectación. Para que sea bello, poético e ideal, lo ingenuo debe ser al mismo tiempo instinto e intención», Schlegel, F., «Fragmentos del Athenaeum, 1798» (51), en: Fragmentos, ed. cit., p. 68. 
las causas que explican la atribución de un tópico como aquél descansan, por una parte, en la lectura que Hegel hiciera de las teorías de sus coetáneos ${ }^{49}$. Pero, también, en la dificultad que autores como F. Schlegel encontraron para poner en práctica tesis como ésta (aspecto por el que siempre se critica a este autor al tratar su concepto de ironía). En cualquier caso, de las palabras recogidas más arriba se deduce que, por un lado, para eludir las limitaciones propias a lo real, el escritor debe sobreponerse a éste y, así, hacerse dueño de su expresión. Y, por otro, que para llevar a cabo dicha tarea, el espíritu (o sujeto reflexivo) cuenta con la capacidad de aunar autocreación y autoaniquilación; una oscilación permanente entre lo propio y lo extraño como estrategia de asedio ante la «imposibilidad y la necesidad de una comunicación completa ${ }^{50}$. Se trata, pues, de un proceso en el que los sentidos terminan por permanecer en suspenso, siempre a la espera de una nueva inversión. Y son esta ambigüedad e interrupción sin límites las particularidades que constituyen el núcleo de lo que el joven $\mathrm{F}$. Schlegel entendía por ironía: un recurso con el que el escritor mantiene la obra en perpetuo devenir entre lo subjetivo y lo objetivo; la necesaria corrección del entusiasmo creativo.

En su estudio sobre El concepto de crítica de arte en el Romanticismo alemán, Walter Benjamin distingue dos modos de comprender la ironía de la Frühromantik. Por un lado, habla de una «ironía del material» con la que el poeta se impone sobre el sistema lingüístico, es decir, el material con el que trabaja, y destruye lo ya creado para tomar distancia y potenciar la raíz crítica - o reflexiva - de la obra. Por otro, se refiere a una «ironía de la forma» en la que se cuestiona la aparente unidad de la obra, afirmando así su inevitable fragmentariedad con respecto a la idea de arte general. En relación a esta última especifica:

En esta clase de ironía, que nace de la relación con lo incondicionado, no se trata por tanto de subjetivismo y de juego, sino de asimilación de la obra limitada a lo absoluto, de su plena objetivación al precio de su ruina. Esta forma de la ironía procede del espíritu del arte, no de la voluntad propia del artista. Se entiende por sí mismo que, al igual que la crítica, sólo puede exponerse en la reflexión. Reflexiva es asimismo la ironización del material, pero ésta estriba en una reflexión subjetiva, lúdica, del autor. La ironía del material aniquila a éste, y es negativa y subjetiva; positiva y objetiva en cambio es la ironía de la forma ${ }^{51}$.

A pesar de que se convocan aquí importantes cuestiones relacionadas con la teoría estética romántica - como el concepto de crítica, de obra artística, de ideal, etc.— que extenderían este estudio demasiado lejos, sí resulta posible, no obstante, extraer algunas ideas aisladas sobre el proceder irónico que permitan comprender su especificidad. Según la exposición benjaminiana, la ironía alberga en sí misma un proceso de afirmación y negación

49 Domingo Hernández Sánchez ha descrito esta situación de un modo fundamental: «Hegel solamente incidió en esta parte subjetiva, olvidando la segunda, la de la autolimitación. [...] Parece como si Hegel hubiera pecado precisamente de ausencia de hegelianismo, de no percibir la dialéctica en su conjunto. Y esto resulta demasiado sospechoso. Lo que realmente parece molestar a Hegel es la traducción a temas estéticos, artísticos y literarios de la teoría fichteana por parte de Schlegel», Hernández Sánchez, D., La ironía estética, ed. cit., p. 69.

50 Schlegel, F., «Fragmentos críticos, 1797» (108), en: Fragmentos, ed. cit., p. 49.

51 Benjamin, W., El concepto de crítica de arte en el Romanticismo alemán, en: Obras, libro I/vol. 1, ed. cit., pp. $84-85$. 
idéntico al que con ella se ejerce, pues, por un lado, la subjetividad del artista se enfrenta a la objetividad de lo creado mediante la ironía del material y, por otro, el carácter singular de toda obra es puesto en relación a la totalidad del arte, gracias a la ironía de la forma. Además, esta discriminación propuesta por Benjamin contribuye a localizar de un modo más preciso los mecanismos con los que el escritor se sirve de la reflexión irónica, ya que, de un lado, esa ironía del material aparece aquí asociada a los juegos, negaciones o arbitrios que el poeta practica sobre el sentido de lo representado y, de otro, la ironía de la forma se vincula con la destrucción de la ilusoria unidad encarnada por la obra. No se trata, por tanto, de simple expresión de una interioridad, sino de reflexión del yo a partir de lo creado. Y esa toma de conciencia que el autor ejerce en el medio del arte poseía, de acuerdo con Benjamin, dos momentos o posturas frente a la obra que implicaban bien la destrucción del material, o bien la destrucción de la forma.

A diferencia de la tradicional ironía retórica, la antifrástica, o de las propuestas de Solger y Kierkegaard, esta ironía no opera con una serie definida de opciones contrarias sobre las que sea imprescindible efectuar una elección, sino que se sitúa más bien en una indefinición constante, donde lo afirmado y su negación nunca se disuelven en una síntesis o respuesta clara. La apuesta por la ambigüedad lingüística instala a la poesía en un perpetuo devenir que hace imposible clausurar sus sentidos, manteniéndolos como algo inagotable. El objetivo primordial sería, pues, hacer que el material lingüístico crezca hasta lo infinito y que los sentidos vayan aumentando en una progresión sin fin, gracias a la anfibología de la palabra. Por ello, la ironía constituye una apuesta incondicional por la ambigüedad. No se busca, pues, resolver el conflicto, sino contribuir a su expansión al presentar, al menos, dos opciones en un mismo plano: «Una idea es un concepto perfecto y acabado hasta la ironía, una síntesis absoluta de antítesis absolutas, la alternancia que se genera a sí misma constantemente de dos pensamientos en conflicto» ${ }^{52}$, afirmaba Schlegel en los «Fragmentos del Athenäeum».

Por otra parte, este tipo de práctica expresaría la voluntad del poeta irónico por manifestar la dependencia que el propio lenguaje mantiene en relación a la actividad creadora del sujeto, y afirmar, con ello, el carácter equívoco de todo contenido lingüístico, dada su condición productiva y no mimética con respecto a lo real. Ciertamente, como sugería Schlegel, la libertad del artista aquí es máxima, llegando incluso a dar la sensación de haberse entregado a una actividad plagada de arbitrio, sólo obediente a su entusiasmo. Sin embargo, esa fuerza creativa infinita encuentra su limitación al exteriorizarse y adoptar una determinada forma escrita. De ahí que el movimiento no se detenga en la pura destrucción o negación perpetua como se señalaba con Kierkegaard, pues Schlegel era muy consciente de que «resulta tan letal para el espíritu tener un sistema como no tener ninguno. Así pues, probablemente tendrá que optar por combinar ambas cosas» ${ }^{53}$.

A partir de tales pautas, logra intuirse fácilmente que aquella ironía de la forma que Benjamin vinculaba a la destrucción de las estructuras artísticas, guarda cierta relación con este modo de desbaratar el principio de no contradicción, practicar la paradoja y mantener al poeta y a su creación en una superación constante de las limitaciones. Por ello, si la ironía del material se practica contra el sujeto, la de la forma se dirige contra la propia obra, a través

52 Schlegel, F., «Fragmentos del Athenaeum, 1798» (121), en Fragmentos, ed. cit., p. 84.

53 Ibíd. (53), p. 69. 
del cuestionamiento continuo de su unidad. En este sentido, será la parábasis la que asuma ahora esa tarea de expansión y crítica incesante. Se trata, precisamente, de aquella ruptura de la ilusión que se anunciaba con Tieck, A. Schlegel y Jean Paul y que, en el seno de la estética romántica, remite al concepto de obra de arte en general, es decir, a la forma de referir la obra de arte particular al conjunto de la creación artística. No obstante, en este punto, interesa su condición de procedimiento discursivo o recurso vinculado a la autolimitación:

el poeta romántico se caracteriza por la conciencia crítica de la limitación y, por lo tanto, de la insuficiencia de toda invención poética singular respecto a la infinita plenitud de la que querría ser expresión. [...] La ironía no es otra cosa que el recurso con el que el poeta mantiene su obra en perpetuo devenir, de modo que pueda ser una obra universal y progresiva ${ }^{54}$.

Y para ello, somete a crítica cualquier estructura estable, negándola y afirmándola de un modo insistente, con el fin de aumentar su capacidad para abarcar la riqueza semántica de lo real. Schlegel calificó la ironía de «bufonería auténticamente trascendental», aunando en esta caracterización tanto su momento subjetivo e infinito de autoposición del sujeto, como el objetivo y limitado de aniquilación, que constituye, «en el exterior, aquella ejecución que presenta el estilo mímico de cualquier buen bufón italiano corriente» ${ }^{55}$. Por su parte, Paul de Man ha interpretado esta «ejecución» en tanto que recurso estilístico con el que el autor rompe la ficción y, por tanto, la apariencia de totalidad de una obra particular. Tal interrupción es lo que, para este teórico, debe entenderse como parábasis - término procedente de la comedia griega-, en la estética romántica, o «desplazamiento en el registro retórico» ${ }^{56}$. En efecto, esta ironía queda así vinculada, para Schlegel, a la comedia y, por tanto, al humor que él mismo identificaba en las obras de sus compañeros Tieck o Jean Paul. Sin embargo, su parentesco con lo cómico no debe hacer pensar que se trata únicamente de un recurso humorístico que pone en evidencia el juego de la representación, pues como ya se ha apuntado la ironía en F. Schlegel va más allá, «su auténtica patria» es la filosofía y «constituye la forma de lo paradójico» ${ }^{57}$; es una estrategia de pensamiento basada en la contradicción, en la continua superación de momentos opuestos. Paolo D’Angelo lo ha resumido del siguiente modo:

este cambio continuo entre la pertenencia absoluta y el distanciamiento, entre la subsunción completa y el completo alejamiento, es precisamente el movimiento característico de la ironía, cuyo sentido más auténtico reside precisamente en la convicción de que tanto en la producción o en el goce de la obra de arte, como en la reflexión filosófica, no es posible, sin más, fundirse con el objeto, perderse en él, o distanciarse absolutamente de él, como si se observara desde fuera, sino que hay que moverse sin cesar de uno a otro polo, sin que sea posible detenerse en uno u otro ${ }^{58}$.

\footnotetext{
54 Sánchez Meca, D., «Friedrich Schlegel y la ironía romántica», art. cit., p. 92.

55 Schlegel, F., «Fragmentos críticos, 1797» (42), en: Fragmentos, ed. cit., p. 35.

56 Man, P. de, «El concepto de ironía», en: La ideología estética, ed. cit., pp. 251-252.

57 Schlegel, F., «Fragmentos críticos, 1797» (42 y 48), en: Fragmentos, ed. cit., pp. 34 y 36, respectivamente.

58 D’Angelo, P., La estética del romanticismo, ed. cit., p. 131.
} 
Por eso, Schlegel la alejaba de la ironía socrática y la retórica, afirmando que «en ella todo debe ser broma y todo debe ser serio, todo debe resultar cándidamente sincero y profundamente simulado a la vez ${ }^{59}$. La parábasis, entonces, mantiene la obra en suspenso, no resuelve el conflicto como sí haría lo cómico, por ejemplo. De ahí que resulte tremendamente complejo atribuir un significado unívoco a esta ironía de la forma, al igual que ocurría con la ambigüedad cultivada desde la palabra poética. Se trata de un planteamiento que evita clausurar los sentidos y mantiene al sujeto en dialéctica constante con su creación, poniendo cotas a su posicionamiento. Por ello, se exije seriedad y humor a un tiempo y no sólo una seriedad fingida como creía Schopenhauer. Parecería, entonces, que al asociar lo que este filósofo entendía por ironía, con lo que describe como humor, la ironía de Schlegel quedaría mucho mejor caracterizada, pues ésta es, como sí supo ver Jankélévitch, tragicómica o, recordando sus propias palabras, «lo-uno-y-lo-otro más que ni-lo-uno-ni-lo-otro». Una «constante autoparodia» que las «personas armónicamente banales» no saben cómo interpretar y que hace que «vayan constantemente de la creencia a la desconfianza hasta marearse y acaben tomando en serio lo que es broma y en broma lo que es serio ${ }^{60}$. Ya que, como se decía, ese ponerse por encima de lo creado implica desconcierto e inestabilidad de sentidos; algo así como la condición y el peligro de la ironía. Y este riesgo inherente al ejercicio de la ironía se traduce en muchos casos en una interpretación parcial de los planteamientos artísticos que se sirven de ella.

En definitiva, lo que estos románticos estarían tratando de nombrar con este concepto es una crítica y extrema autoconciencia - por parte del sujeto- de lo limitado de su creación, así como su intento por trascenderlo. Aquel «conflicto indisoluble entre lo condicionado y lo incondicionado, de la imposibilidad y la necesidad de una comunicación completa» ${ }^{61}$ que se veía con Schlegel. Una postura que este autor limita a la poesía moderna, a la que calificaba de química, en clara oposición a la naturaleza orgánica de la Antigüedad ${ }^{62}$, y que sin lugar a dudas ha determinado igualmente a un amplio sector de la actividad artística contemporánea.

No obstante, todos estos mecanismos empleados para el fomento de la alusión, la connotación, la ambivalencia y la apertura, que en la mayoría de esas poéticas románticas detentaban una valoración altamente positiva, han sido puestos en entredicho por buena parte de los estudios literarios que, tras el primer romanticismo alemán, han investigado la práctica irónica. Lo que allí se vio como deseo de violentar las exégesis más cómodas, va a encontrar una marcada oposición en la Crítica y la Teoría literaria internacional, que no aceptará mantener tales espacios de indeterminación en la literatura ${ }^{63}$. En este sentido, y tras esa larga

59 Schlegel, F., «Fragmentos críticos, 1797» (108), en: Fragmentos, ed. cit., p. 49.

60 Ibíd.

61 Ibíd.

62 Cf. Schlegel, F., «Fragmentos del Athenaeum, 1798» (426), en: Fragmentos, ed. cit., pp. 179-180. Por su parte, Peter Szondi ha vinculado esta visión de la Modernidad como conjunto artificial, antes que un todo natural, con la noción de ironía schlegeliana, en Szondi, P., Poética y filosofía de la historia I, ed. cit., p. 82. Asimismo, es bien conocido que Peter Bürger relacionó esta noción de obra "inorgánica” con las prácticas artísticas de vanguardia y determinados procedimientos alegóricos, en oposición a la idea de obra "orgánica” y simbólica, que asume una adecuación total entre el todo y las partes (cf. Bürger, P., Teoría de la vanguardia, Barcelona, Península, 2000, p. 112).

63 Cf. Muecke, D. C., The compass of Irony, London-New York, Methuen, 1980 (reimpr. de 1969) y Irony and the ironic, London-New York, Methuen, 1982; Booth, W. C., Retórica de la ironía, Madrid, Taurus, 1989 o 
etapa de reflexión filosófica en torno al origen, valor y función de la ironía, la especulación teórica de mediados y finales del siglo XX se centrará más bien en aquellos indicadores lingüísticos (verbales y no verbales) que evidencian la presencia de este fenómeno y menos en los propósitos asociados a tal procedimiento. Por tanto, lo esencial en estos nuevos enfoques no será señalar la naturaleza de la ironía, como hiciera Schlegel, sino lograr establecer unos criterios estables para su correcto reconocimiento e interpretación. A pesar de ello, lo cierto es que gran parte de las prácticas artísticas contemporáneas no han querido renunciar a esa idea de indeterminación impulsada por Schlegel y han seguido fomentando un uso perturbador y no conciliatorio de lo irónico. Dejando a un lado, pues, determinados discursos asociados a cierto relativismo posmoderno, que también quiso apropiarse de una noción de ironía demasiado tranquilizadora como para ser asimilada a la schlegeliana, continúa siendo necesario preguntarse por el alcance $-\mathrm{y}$ la filiación romántica - de este procedimiento, en algo tan actual dentro del campo artístico como es la expansión de sus propios límites.

Brooks, C., The Well Wrought Urn: Studies in the Structure of Poetry, New York, Harcourt, Brace \& World, 1947 y «Irony as a Principle of Structure», en: Rick Rilance (ed.), Debating texts. A reader in twentieth-century Literary Theory and Method, Toronto, University of Toronto Press, 1987. 
